\title{
Cloning the ribosomal RNA operons of Mycoplasma flocculare and comparison with those of Mycoplasma hyopneumoniae
}

\author{
G. W. Stemke, ${ }^{1}$ Y. Huang, ${ }^{1}$ F. Laigret ${ }^{2}$ and J. M. Bové ${ }^{2}$ \\ Author for correspondence: G. W. Stemke. Tel: +1 403492 3277. Fax: +1 4034922216.
}

1 Department of
Microbiology, University of
Alberta, Edmonton,
Alberta, Canada T6G 2E9
2 Laboratoire de Biologie
Cellulaire et Molécular,
INRA and Université de
Bordeaux II, 33883,
Villenave d'Ornon, France

\begin{abstract}
In contrast to other mycoplasma species the 165/235 rRNA and 5S rRNA operons of Mycoplasma flocculare and Mycoplasma hyopneumoniae map at least $150 \mathrm{~kb}$ apart (20\% of the genome). Both operons from $M$. flocculare have been cloned and sequenced. The 235 rRNA gene sequence showed $96.7 \%$ homology with the corresponding gene of $\boldsymbol{M}$. hyopneumoniae, equalling that found earlier for 165 rRNA and confirming the close phylogenetic relationships of these organisms. A possible upstream promoter was identified. Sequence elements upstream and downstream from each structural gene could form a stem needed for maturation of the immature rRNA transcript to mature 165 and 235 rRNA. We also identified two possible stem-and-loop sequences 3' to the 235 rRNA gene. The 5S rRNA gene itself also showed high homology with the corresponding structural gene of $M$. hyopneumoniae, although the upstream and downstream sequences were highly heterologous.
\end{abstract}

Keywords: Mycoplasma flocculare, Mycoplasma byopneumoniae, rRNA operons, 23S
Because the rRNA genes are among the most conserved genetic elements, comparisons of these sequences have become important phylogenetic tools (Olsen \& Woese, 1993). In a recent report we used $16 \mathrm{~S}$ rRNA sequence comparisons to analyse phylogenetic relationships between three porcine mycoplasmas: Mycoplasma byopneumoniae, $M$. flocculare and $M$. byorbinis. We demonstrated that these mycoplasmas were closely related, particularly $M$. byopneumoniae and M. flocculare (Stemke et al., 1992). Another common property of these two organisms was that, unlike other mycoplasma species, the $16 \mathrm{~S} / 23 \mathrm{~S}$ rRNA region was separated from the $5 \mathrm{~S}$ rRNA gene (Taschke et al., 1986). The physical maps of the genomes of both organisms have been established and the $16 \mathrm{~S} / 23 \mathrm{~S}$ and $5 \mathrm{~S}$ rRNA genes located (Huang \& Stemke, 1992). Here we report the sequence of the $16 \mathrm{~S} / 23 \mathrm{~S}$ region as well as the $5 \mathrm{~S}$ rRNA region of $M$. flocculare and compare these to their counterparts in $M$. byopneumoniae.

M. flocculare strain Ms42 (ATCC 27716) was grown in modified Friis broth (Friis, 1975) and harvested as previously described (Stemke et al., 1992). DNA was prepared from the washed cell pellet using the method of Gross-Bellard et al. (1973).

The GenBank accession numbers for the sequences reported in this paper are L22210 and U01070.
The M13mp19 vector containing the 5S rRNA gene of $M$. flocculare was selected by probing with a $M$. byopneumoniae 5S-rRNA-specific oligonucleotide (5'-TGAATCCATTCCGAACT-3' ${ }^{\prime}$. The replicative form of the recombinant phage containing a 665 bp $\mathrm{XbaI}$ fragment was sequenced using the Pharmacia dideoxy sequencing kit following the double-strand sequencing protocol.

The $16 \mathrm{~S} / 23 \mathrm{~S}$ rDNA sequences were obtained from an EcoRI partial digest fragment of $M$. flocculare DNA cloned into pBlueScript as previously described (Stemke $e t$ al., 1992). A portion of the sequence of the $12 \mathrm{~kb}$ insert was determined as above. Primer extension was employed to extend the $M$. flocculare $16 \mathrm{~S}$ rRNA sequence.

The sequence for the 23S rRNA of $M$. byopneumoniae was obtained from GenBank as accession number X68421. The sequences for the $M$. byopneumoniae $5 \mathrm{~S}$ rRNA gene and $16 \mathrm{~S} / 23 \mathrm{~S}$ rRNA intergenic region were taken directly from Taschke \& Herrmann (1986). The sequences for the $16 \mathrm{~S} / 23 \mathrm{~S}$ rRNA genes and the 5S rRNA gene of $M$. flocculare have been deposited as GenBank accession numbers L22210 and U01070, respectively.

The $665 \mathrm{bp}$ sequence of the cloned XbaI fragment was determined and compared with the corresponding $M$. byopneumoniae 5S rRNA sequence. A 106 bp sequence representing the $5 \mathrm{~S}$ rRNA structural gene was found to have $95 \cdot 3 \%$ homology with the $M$. byopneumoniae gene. Fig. 1 shows this homology and the possible promoters 


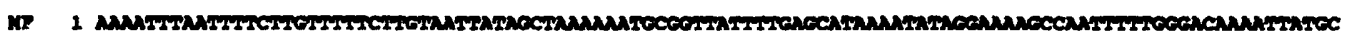

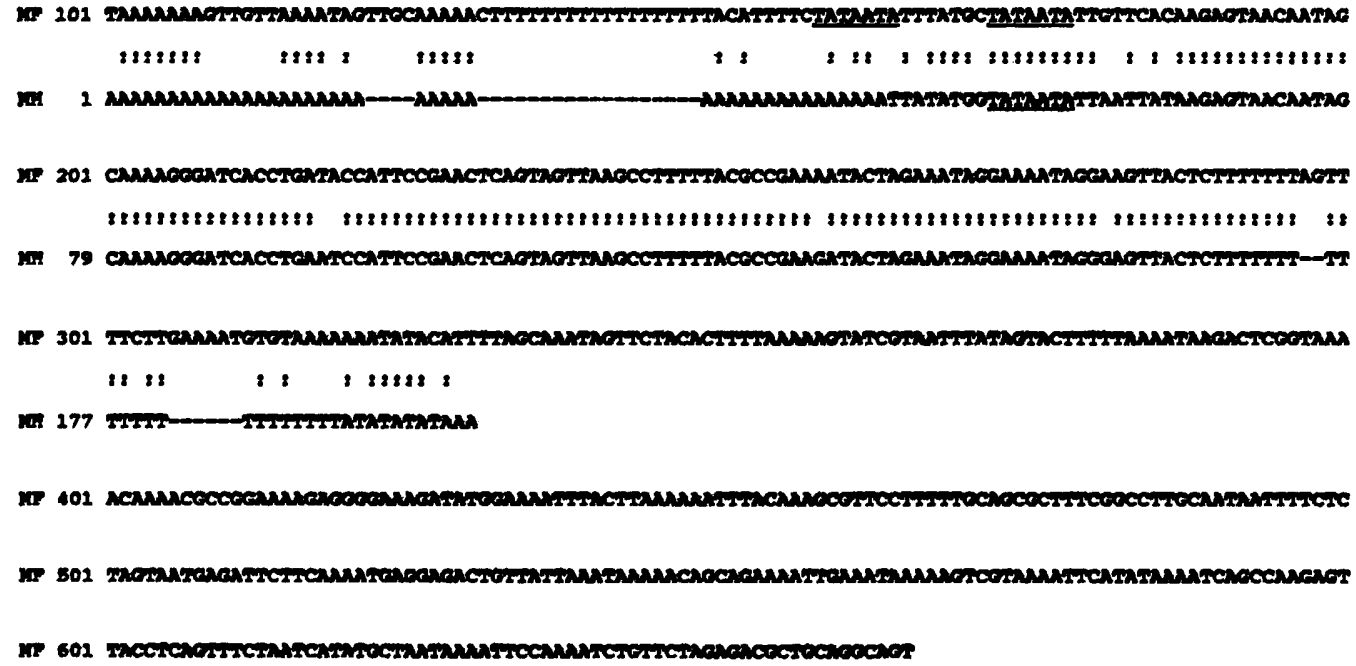

Fig. 1. Alignment of the $5 S$ rRNA genes of $M$. flocculare and $M$. hyopneumoniae. MF, $M$. flocculare; $M H, M$. hyopneumoniae. (:), Sequence identity. Underlined are possible promoters of each species.

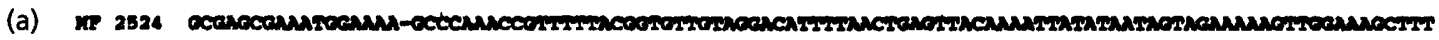

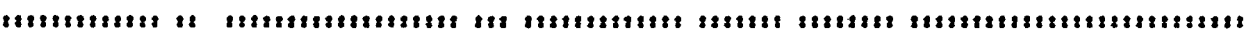

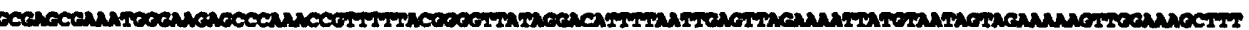

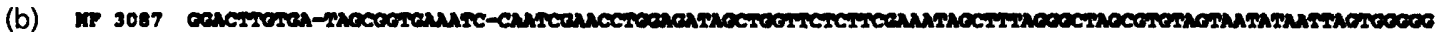

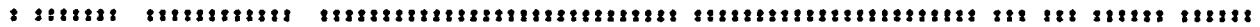

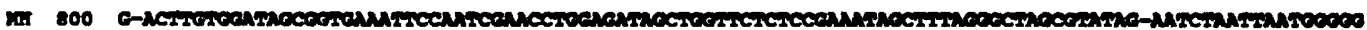

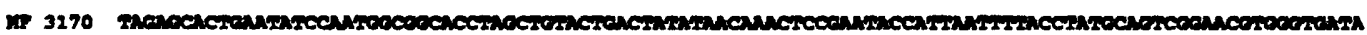

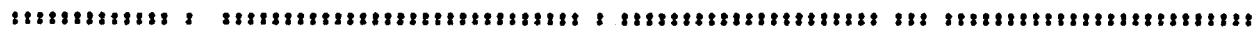

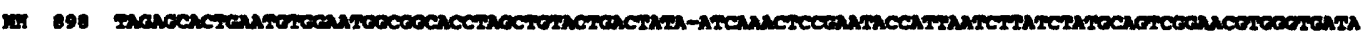

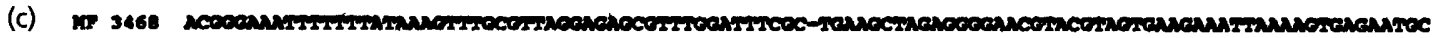

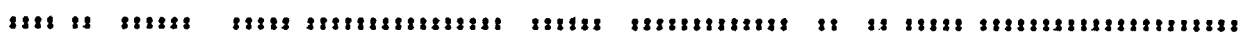

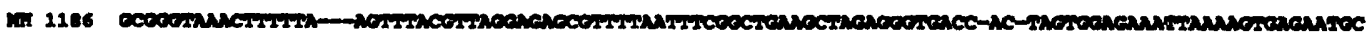

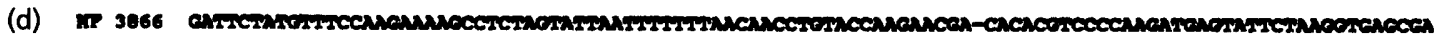

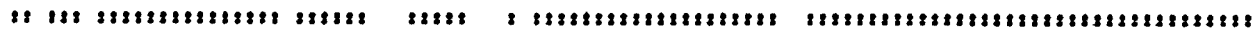

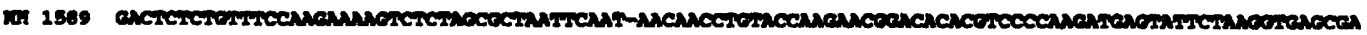

Fig. 2. Alignment of selected regions of $M$. flocculare and $M$. hyopneumoniae 235 rRNA genes with relatively large sequence variation. MF, $M$. flocculare; $M H, M$. hyopneumoniae. (:), Sequence identity. Numbering for $\mathrm{MH}$ was taken from GenBank accession number X68421.

for the $M$. flocculare gene. Two upstream TATAA Pribnow box sequences were noted, one directly homologous to the $M$. byopneumoniae promoter at the -10 position but preceded by another TATAA sequence at the -25 position. Except for the -10 region, the lack of homology in both the upstream and downstream regions of these genes is very apparent. More sequence information for both species both upstream and downstream of that presently available and determination of other genetic markers above and below these sequences 


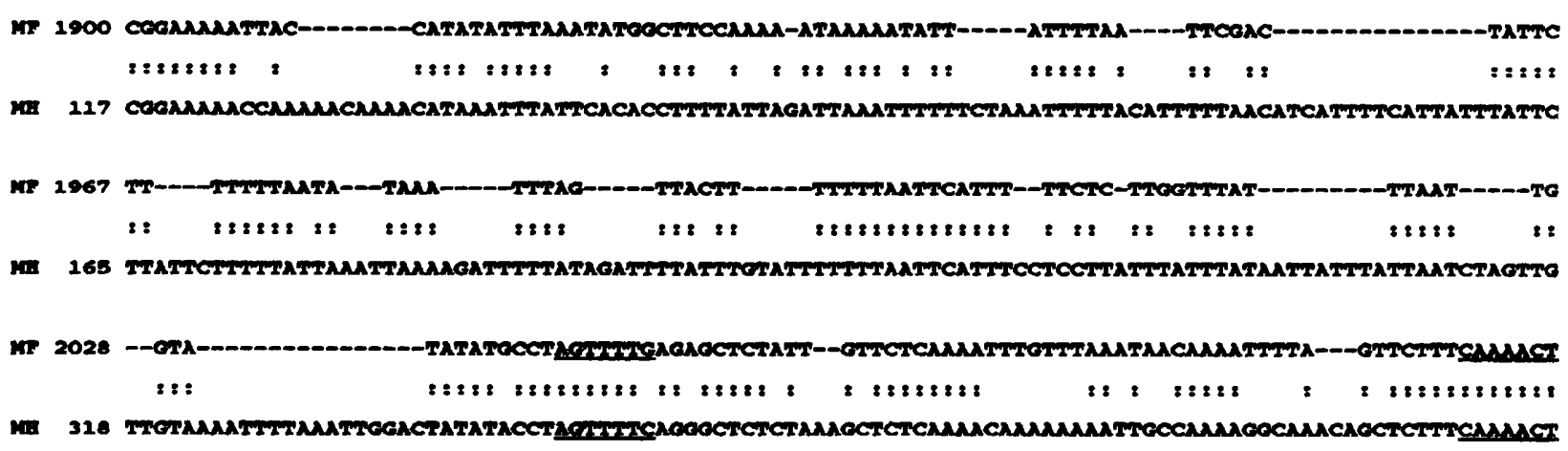

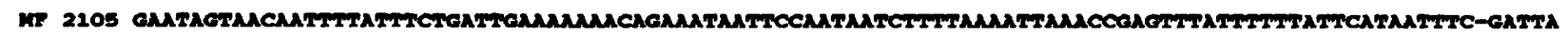

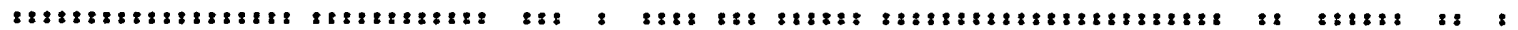

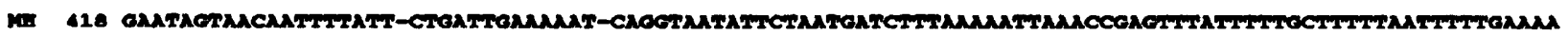

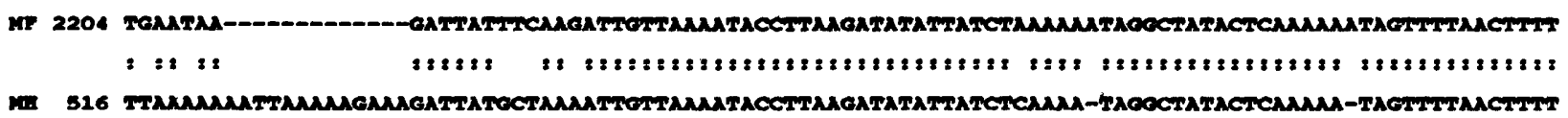

MF 2291 тגAatraAтגac

$2828,828,8$

10.

тматматмас

Fig. 3. Sequence homology comparison of $M$. flocculare and $M$. hyopneumoniae $165 / 235$ rRNA intergenic regions. MF, $M$. flocculare; $\mathrm{MH}, M$. hyopneumoniae. Numbering for $\mathrm{MH}$ was taken from Taschke \& Herrmann (1986; Fig. 3(B) intergenic region). Underlined regions are possible rRNA maturation stem-forming sequences; the single nucleotide difference is compensated by a corresponding change in the region upstream of the $16 \mathrm{~S}$ rRNA structural sequence.

will be required to verify these conclusions and judge their significance.

For the $16 \mathrm{~S} / 23 \mathrm{~S}$ region, a total of 5459 nucleotides was determined, including the $16 \mathrm{~S}$ rRNA sequence already reported as GenBank accession number X63377. Only two other mycoplasma $23 \mathrm{~S}$ rRNA genes have been totally sequenced: those of $M$. pneumoniae and $M$. byopneumoniae (Ludwig et al., 1992). Using the Nalign program of PcGene, homology with $M$. byopneumoniae was $96.7 \%$ for the $23 \mathrm{~S}$ gene, similar to that found with the $16 \mathrm{~S} \mathrm{rRNA}$ sequence comparison (Stemke et al., 1992). Both $5^{\prime}$ and $3^{\prime}$ ends of this sequence were even more highly conserved for these two species; only four nucleotides in the first 235 $5^{\prime}$ nucleotides and four in the last 561 nucleotides at the $3^{\prime}$ end showed variation. Fig. 2 indicates areas of greater diversity found in interior regions.

The $16 \mathrm{~S} / 23 \mathrm{~S}$ intergenic region of $M$. flocculare (403 bp) was 105 bp shorter than that of M. byopneumoniae (Taschke \& Herrmann, 1986). However, the two sequences could be aligned by the introduction of large (greater than four nucleotide) gaps to the $M$. flocculare sequence; after these adjustments, homology was calculated as $82.9 \%$. As seen in Fig. 3, homology was greatest in the $3^{\prime}$ half of this region. The rRNA operons of prokaryotes typically contain the 16S, $23 \mathrm{~S}$ and 5S rRNA genes (in this order) with $t R N A$ genes located in the first intergenic region. All Mycoplasma and Ureaplasma species (Harasawa et al., 1992) deviate from this organization in that no tRNA genes occupy the intergenic region. Our data indicate that this is also true for $M$. flocculare.

At least four possible promoter sites occupy the region upstream of the $16 \mathrm{~S}$ rRNA gene (2, 98, 155 and 323); the AT-rich nature of the mollicute genome makes the random frequency of the TATAA sequence quite high. However, at nucleotide 155 is TATAATG, differing only in its final $\mathrm{G}$ from the TATAATA suggested by Taschke \& Herrmann (1986) to be one of the promoters for the $M$. byopneumoniae rrn locus.

Upstream of the $M$. flocculare $16 \mathrm{~S}$ and $23 \mathrm{~S}$ sequence at positions 311 and 2098, respectively, is the sequence CAAAACT; downstream of the $16 \mathrm{~S}$ (position 2040) and $23 \mathrm{~S}$ (position 5226) sequence is the exact inverted complement, AGTTTTG. These are required to form a portion of the stems for the maturation of the RNA transcript to mature $16 \mathrm{~S}$ and $23 \mathrm{~S}$ rRNA (Taschke \& Herrmann, 1986). As shown in Fig. 3, and marked by underlining, these sequences are highly conserved in the intergenic region between the $16 \mathrm{~S}$ and $23 \mathrm{~S}$ rRNA structural genes for $M$. flocculare and $M$. byopneumoniae. Between positions 5256 and 5299, and between 5341 and 5380 , are probable 'hairpins' which may be a portion of the termination signal, although in neither case is the GC content high. Thus, all elements required for transcription and maturation of a separate $16 \mathrm{~S} / 23 \mathrm{~S}$ operon are present in this sequence. This is expected since, as indicated above, the $5 \mathrm{~S} \mathrm{rRNA}$ gene is over $150 \mathrm{~kb}$ removed in the 
DNA of both species from the 16S/23S rRNA genes (Taschke et al., 1986; Stemke et al., 1992).

\section{REFERENCES}

Friis, N. F. (1975). Some recommendations concerning primary isolation of Mycoplasma suipneumoniae and Mycoplasma flocculare. Nord Veterinaermed 27, 337-339.

Gross-Bellard, M., Oudet, P. \& Chambon, P. (1973). Isolation of high molecular weight DNA from mammalian cells. Eur $J$ Biochem 36, 32-38.

Harasawa, R., Uemori, T., Asada, K., Kato, I. \& Shiragami, N. (1992). 'boxA'-like sequence between the $16 \mathrm{~S} / 23 \mathrm{~S}$ spacer in $\mathrm{rRNA}$ operon of mycoplasmas. FEBS Lett 297, 209-211.

Huang, Y. \& Stemke, G. W. (1992). Construction of the physical maps of Mycoplasma byopneumoniae and Mycoplasma flocculare and the location of rRNA genes on these maps. Can J Microbiol 38, 659-663.

Ludwig, W., Kirchhof, G., Klugbauer, N., Weizenegger, M., Bextzl, D., Ehrmann, M., Hertel, C., Jilg, S., Tatzel, R., Zitzelsberger, H., Liebl, S., Hochberger, M., Shah, J., Lane, D.,
Wallnofer, P. R. \& Scheifer, K. H. (1992). Complete 23 S ribosomal RNA sequences of Gram-positive bacteria with a low DNA G +C content. Appl Microbiol 15, 487-501.

Olsen, G. J. \& Woese, C. R. (1993). Ribosomal RNA - a key to phylogeny. FASEB J 7, 113-123.

Stemke, G. W., Laigret, F., Grau, O. \& Bovè, J. M. (1992). Phylogenetic relationships of three porcine mycoplasmas, Mycoplasma byopneumoniae, Mycoplasma flocculare, and Mycoplasma byorbinis, and complete $16 \mathrm{~S}$ rRNA sequence of $M$. flocculare. Int J Syst Bacteriol 42, 220-225.

Taschke, C. \& Herrmann, R. (1986). Analysis of transcription and processing signals of the 16S-23S rRNA operon of Mycoplasma byopneumoniae. Mol \& Gen Genet 205, 434-441.

Taschke, C., Klinkert, M. Q., Wolters, J. \& Herrmann, R. (1986). Organization of the ribosomal RNA genes in Mycoplasma byopneumoniae: the $5 \mathrm{~S}$ rRNA gene is separated from the $16 \mathrm{~S}$ and $23 \mathrm{~S}$ rRNA genes. Mol \& Gen Genet 205, 428-433.

Received 14 September 1993; revised 15 November 1993; accepted 17 December 1993. 